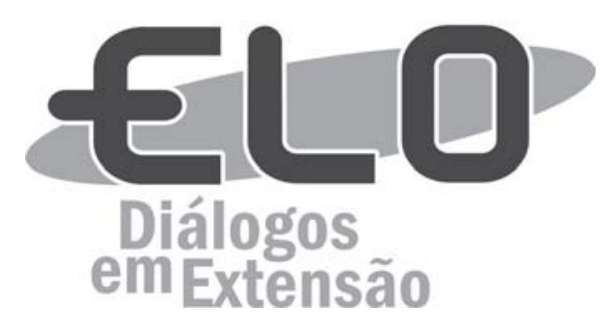

\title{
Técnicas de baixo custo para aproveitamento de água de chuva e reúso de água cinza: o início de uma cultura de conservação da água em Rio Paranaíba-MG
}

\author{
Vitor Luís Amorim Fonseca ${ }^{1}$, Rejane Nascentes ${ }^{2}$, Lorena Taís Caixeta ${ }^{3}$
}

\begin{abstract}
Resumo: Devido ao crescimento populacional, há uma pressão cada vez maior nos mananciais hídricos e, consequentemente, haverá racionamentos mais frequentes e mais longos. Com isso, existe a necessidade de pesquisar tecnologias que sejam capazes de aliviar a demanda de água dos mananciais, das quais podem ser citadas as fontes alternativas ao abastecimento convencional. São elas, principalmente, o aproveitamento da água de chuva e o reúso de água cinza. Nesse aspecto, buscaram-se técnicas direcionáveis às residências que não necessitam de custo alto para serem implementadas. Portanto, este projeto, apoiado pela Universidade Federal de Viçosa, através do PIBEX, teve o intuito de pesquisar e, por meio de palestras oferecidas à população, disseminar essas práticas aos moradores de Rio Paranaíba-MG. Com três palestras e 45 pessoas alcançadas, o projeto iniciou uma cultura de conservação da água na cidade.
\end{abstract}

Palavras-chave: Água de chuva. Água cinza. Educação ambiental. Sustentabilidade.

Área Temática: Meio ambiente, Educação, Tecnologia.

\section{Low-cost techniques for the use of rainwater and gray water reuse: the beginning of a water conservation culture in Rio Paranaiba-MG}

\begin{abstract}
Due to population growth, there is an increasing pressure on water sources and, consequently, there will be more frequent and longer rationing. With this, there is a need to research technologies that are able to alleviate the water demand of the sources, from which alternative sources can be cited to the conventional supply. They are, mainly, the use of rainwater and the reuse of gray water. In this aspect, we searched for techniques directed to the residences that do not need high cost to be implemented. Therefore, this project, supported by the Federal University of Viçosa, through the PIBEX, aimed to research and, through lectures offered to the population, disseminate these practices to residents of Rio Paranaiba-MG. With three lectures and 45 people reached, the project initiated a culture of water conservation in the city.
\end{abstract}

Keywords: Rain water. Grey water. Environmental education. Sustainability.

\section{Técnicas de bajo costo para el aprovechamiento de agua de lluvia y reutilización de} agua gris: el inicio de una cultura de conservación del agua en Rio Paranaíba-MG

Resumen: Debido al crecimiento poblacional, hay una presión cada vez mayor en los manantiales hídricos y, por lo tanto, habrá racionamiento más frecuente y más largo. Con ello, existe la necesidad de investigar tecnologías que sean capaces de aliviar la demanda de agua de los manantiales, de las cuales pueden ser citadas las fuentes alternativas al abastecimiento convencional. Son, principalmente, el aprovechamiento del agua de lluvia y el reubrimiento de agua gris. En este aspecto, se buscan técnicas direccionables a las

\footnotetext{
${ }^{1}$ Universidade Federal de Viçosa Campus Rio Paranaíba. Estudante de Graduação em Engenharia Civil e bolsista do projeto. Rua Ibiá, n 190, ap. 202, Bairro Progresso - Rio Paranaíba/MG, Brasil. (34) 99127-8207. E-mail: vitor.amorimcivil@gmail.com.

${ }^{2}$ Universidade Federal de Viçosa Campus Rio Paranaíba. Professora do Departamento de Engenharia Civil e Coordenadora do Projeto. E-mail: rejane.nascentes@ufv.br

${ }^{3}$ Universidade Federal de Viçosa Campus Rio Paranaíba. Estudante de Graduação em Engenharia Civil e voluntária do projeto. E-mail: lorenataiscaixeta@gmail.com
} 
residencias que no necesitan de costo alto para ser implementadas. Por lo tanto, este proyecto, apoyado por la Universidad Federal de Viçosa, a través del PIBEX, tuvo el propósito de investigar y, por medio de conferencias ofrecidas a la población, diseminar estas prácticas a los habitantes de Rio Paranaíba MG. Con tres conferencias y 45 personas alcanzadas, el proyecto inició una cultura de conservación del agua en la ciudad.

Palabras clave: Agua de lluvia. Agua gris. Educación ambiental. Sostenibilidad.

\section{Introdução}

Em um relatório publicado em 2015 pela Organização das Nações Unidas (ONU Brasil, 2015) há o alerta de que, até 2030, a demanda mundial por água será $40 \%$ superior que a oferta. Conforme os dados que a Instituição publicou no mesmo relato, 748 milhões de pessoas em todo o planeta ainda não tinham acesso a fontes de água potável de qualidade. Além do mais, até 2050, por consequência do aumento da população mundial, a agricultura terá a necessidade de aumentar a produção em $100 \%$ e, em relação à indústria, sua demanda por água aumentará $400 \%$.

De fato, como apresenta May (2004), o crescimento populacional, que em cidades maiores pode ocorrer de maneira desordenada, e o aumento da demanda por água são as principais causas para o aumento do consumo desse recurso. No Brasil, ao analisar os indicadores da projeção da população no período de 2000-2060, consoante IBGE (2013), nota-se que haverá aumento de habitantes, em nível ainda acelerado, até metade da década de 2030, quando reduzirá a taxa. Essa tende a decrescer a partir da metade da década de 2040.

“Com o crescimento populacional, aumentou a necessidade de água para abastecimento, agricultura de maior escala para alimentar a crescente população, criação de mais indústrias que consomem mais água" (CUNHA et al, 2011). De forma semelhante pensam Dantas \& Sales (2009), apresentando o alerta para a eminente escassez da água frente aos motivos já citados e, ainda, os desmatamentos, uso inadequado do solo, poluição e degradação dos mananciais.

Considerando isso, Munhoz (2006) propõe que haja a busca em equilibrar oferta e demanda de água, a fim de que o desenvolvimento econômico e social seja pautado nos princípios de sustentabilidade. Ainda segundo o autor, para que isso seja possível, são necessários o desenvolvimento e a aplicação de fontes alternativas ao abastecimento convencional. Tais fontes são definidas como "aquelas que não estão sob concessão dos órgãos públicos ou que não sofrem cobrança pelo uso" (MUNHOZ, 2006).

Nesse sentido, Hespanhol (2002) coloca que essas medidas são as mais capazes de suprir consumos menos restritivos, fato que cede águas de melhor qualidade para atividades mais nobres, como o abastecimento doméstico. Reservando essas águas é possível aliviar a tamanha pressão exercida sobre os mananciais.

Tendo em vista a diminuição de água disponível, conforme Cunha et al (2011), os sistemas que serão mais empregados são o aproveitamento de água da chuva e o reúso de água cinza. Para May (2009) essas duas práticas são maneiras de conservar a água potável. Em relação às edificações, conforme Cuba \& Manzano (2014), os métodos de conservação da água abrangem desde práticas de uso racional da água até o aproveitamento de água de chuva ou reúso de água cinza.

O aproveitamento de águas de chuva, como considera Hafner (2007), é de grande potencial, principalmente em países tropicais que possuem médias de precipitação altas durante o ano, como é o caso do Brasil. A autora ainda analisa que esse tipo de fonte alternativa tem a interessante vantagem de prevenir inundações, frequentes em grandes centros, além da economia de água potável devido ao fato que utiliza a água de chuva para finalidades não potáveis.

“As águas cinza são aquelas provenientes dos lavatórios, chuveiros, tanques e máquinas de lavar roupa e louça" (FIORI et al, 2006). Fiori et al (2004) e Cunha et al (2011) exemplificam que o reúso é implantar uma estação de tratamento da água originada de usos nobres, como máquina de lavar roupas e banho, e redistribuir para usos menos nobres como descargas e lavagens de pisos.

É necessário, no entanto, que essas práticas sejam de conhecimento de toda a população e estejam ao alcance dela, seja qual for a classe social. Nota-se, dessa maneira, que o alto custo que, geralmente, é encontrado nos métodos convencionais é um obstáculo, mostrando o quanto é essencial a iniciativa de pesquisar e disseminar as técnicas de baixo custo. Esse projeto, por meio do Programa Institucional de Bolsas de Extensão Universitária (PIBEX), que ocorreu de $1^{\circ}$ de março de 2017 a 30 de novembro do mesmo ano, pesquisou procedimentos voltados, principalmente, às residências, não sendo necessários materiais sofisticados ou mão de obra especializada, por exemplo. 
Quanto a uma tecnologia social, para ser colocada em prática em um projeto de extensão, é possível colocar, como fundamentais, tais características:

Visa solucionar/minimizar um problema significativo da população; baixo custo; não prejudica o meio ambiente e a população ao entorno; a população é capaz de reproduzi-la e transmiti-la para outras pessoas; eficiente; instalação e manutenção simples; possibilidade de a população modificar/adaptar de forma criativa; materiais e insumos baratos, simples e acessíveis; a população reconhece sua utilidade e importância. (ANDREOLI, 2016).

Dessa forma, o presente projeto de extensão buscou desenvolver uma cultura de conservação da água através as práticas de aproveitamento de água de chuva e reúso de água cinza, na região de Rio Paranaíba, município do estado de Minas Gerais. Isso foi feito por meio da divulgação das técnicas utilizadas através de palestras e de suporte técnico especializado. Optou-se por priorizar as técnicas de baixo custo, tornandose, assim, viável a instalação desses sistemas nas residências dos moradores da cidade.

\section{Objetivos}

\section{Objetivo Geral}

Fornecer apoio à disseminação de técnicas de baixo custo para o aproveitamento de água de chuva e reúso de água cinza aos moradores de Rio Paranaíba.

\section{Objetivos Específicos}

- Investigar as técnicas de aproveitamento de água de chuva e reúso de água cinza;

- selecionar as alternativas para esses fins que sejam de baixo custo e, ainda, direcionáveis às residências;

- conscientizar a população da necessidade de utilizar fontes alternativas de abastecimento de água para aliviar a demanda de água dos mananciais.

\section{Metodologia}

\section{Estruturação das palestras}

Ao longo do primeiro semestre de 2017 o projeto dedicou-se à pesquisa bibliográfica, com foco na montagem das palestras. O desenvolvimento dessas passou por uma extensa revisão da literatura, não somente em torno das técnicas de baixo custo para o aproveitamento de água da chuva e reúso de água cinza, mas, também, em relação a conceitos básicos do assunto, com o objetivo de conscientizar a população acerca da necessidade do uso de fontes alternativas ao abastecimento convencional.

Primeiramente, a pesquisa dedicou-se às fontes alternativas ao abastecimento convencional. $\mathrm{O}$ que são tais fontes, a crise hídrica que diversas regiões do país enfrentam e o quanto o uso dessas fontes podem auxiliar a resolver esse problema, partindo tanto do ambiente residencial quanto da indústria. $\mathrm{O}$ estudo concentrou-se, também, em conhecer melhor sobre o ponto de vista de diversos autores sobre o tema do reúso de água, o conceito e os benefícios.

É essencial que os participantes das palestras criassem um conceito bem formado em torno das técnicas de aproveitamento de água da chuva e reúso de água cinza não somente aquelas de baixo custo. Então, deu-se importância, da mesma forma, aos componentes básicos que todo sistema de aproveitamento das águas citadas deve contar, seja convencional ou de baixo custo. Por fim, buscouse, tanto no mercado quanto na literatura, as práticas que fossem de custo inferior às convencionais e específicas para o ambiente residencial.

Em relação ao reúso das águas cinza no ambiente residencial, o projeto teve como referência, principalmente, o "Manual para aproveitamento emergencial de águas cinza do banho e da máquina de lavar" (ALVES et al., 2016). Já para o aproveitamento da água de chuva baseou-se no "Manual para captação emergencial e uso doméstico de água de chuva" (ZANELLA, 2015) e no "Projeto experimental de aproveitamento de água da chuva com a tecnologia da minicisterna para residência urbana" (URBANO, 2014). 


\section{Desenvolvimento dos materiais didáticos}

As palestras foram estruturadas com auxílio das ferramentas de apresentações em slides. Foram utilizadas bastantes ilustrações, priorizando aquelas de melhor qualidade e, até mesmo, confeccionadas pelos próprios autores e, ainda, usufruindo dos recursos de animações e transições. Essas decisões foram com o objetivo de fazer as palestras serem mais dinâmicas e interessantes para os presentes e, dessa forma, uma melhor assimilação dos assuntos discutidos.

Como já citado, a minicisterna, de Urbano (2014), foi bastante discutida e apresentada nas palestras. Visto a facilidade de construção, tanto em relação à mão de obra quanto à aquisição dos materiais necessários, o projeto teve a iniciativa de construir um protótipo da tecnologia. Esse exemplar foi construído em proporções menores que um sistema construído para utilização residencial, tendo o objetivo de demonstrar, detalhadamente, a função de cada componente. É necessário citar, ainda, que esse modelo é utilizado, também, de forma semelhante para o uso e armazenamento das águas cinza.

Além disso, foi pensado, também, em fornecer aos participantes das palestras um material para auxiliálos a colocar em prática as técnicas discutidas de forma correta. Para isso, foi confeccionado um modelo de cartilha que é, basicamente o que foi abordado nas palestras de forma resumida e focando, principalmente, nas práticas de baixo custo para aproveitamento da água de chuva e reúso de águas cinza.

\section{Palestras oferecidas}

Tendo em vista a área temática do projeto, a primeira palestra foi oferecida aos alunos do curso de Engenharia Civil matriculados, no segundo semestre de 2017, na disciplina Ciências Ambientais (ECV 220), como pode ser visto na Figura 2a. Essa palestra foi muito interessante pois houve bastante participação dos alunos, que já haviam discutido temas semelhantes ao longo da disciplina, com o levantamento de suas experiências, principalmente dentro de suas próprias casas.

Para atender a população de Rio Paranaíba, foi planejado oferecer mais duas palestras. Procurouse, primeiramente, a equipe da unidade da UAITEC $^{4}$ da cidade que, prontamente forneceu o local para a realização da palestra, e a outra no campus da UFV na cidade.

Antes do oferecimento do evento, no entanto, foi pensado em fazer uma divulgação em grande escala. Foi criado, assim, um informativo, visto na Figura 1, que foi impresso e colado em murais de locais de grande movimento como a Câmara dos Vereadores, Prefeitura, Secretaria de Educação e UFV-CRP. Além disso, com o apoio da Rádio Maximus, foi feita a divulgação por meio da programação da rádio e, também, em seu site ${ }^{5}$, os quais possuem o acompanhamento frequente da população. Através da Comunicação Social da Universidade, foi feita a divulgação por meio das mídias sociais.

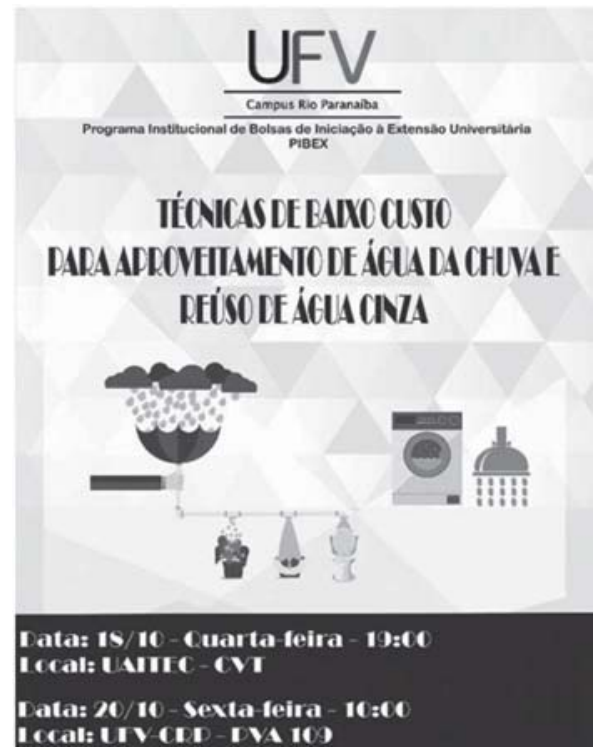

Figura 1 - Informativo de divulgação das palestras.

Fonte: Elaborado pelos autores, 2017.

${ }^{4}$ Universidade Aberta e Integrada de Minas Gerais. O site oficial da instituição pode ser acessado pelo link: <goo.gl/fxcJ5y>. Acesso em: 12 fev. 2018.

${ }^{5}$ A matéria de divulgação, no site da Rádio Maximus, pode ser visualizada através o link: <goo.gl/H69JeF>. Acesso em: 12 fev. 2018. 
Como já citado, foram, então, oferecidas mais duas palestras, como pode ser verificado na Figura 2. Nessas também houve satisfatória participação das pessoas que acompanharam as palestras, com exposições de ideias e dúvidas.
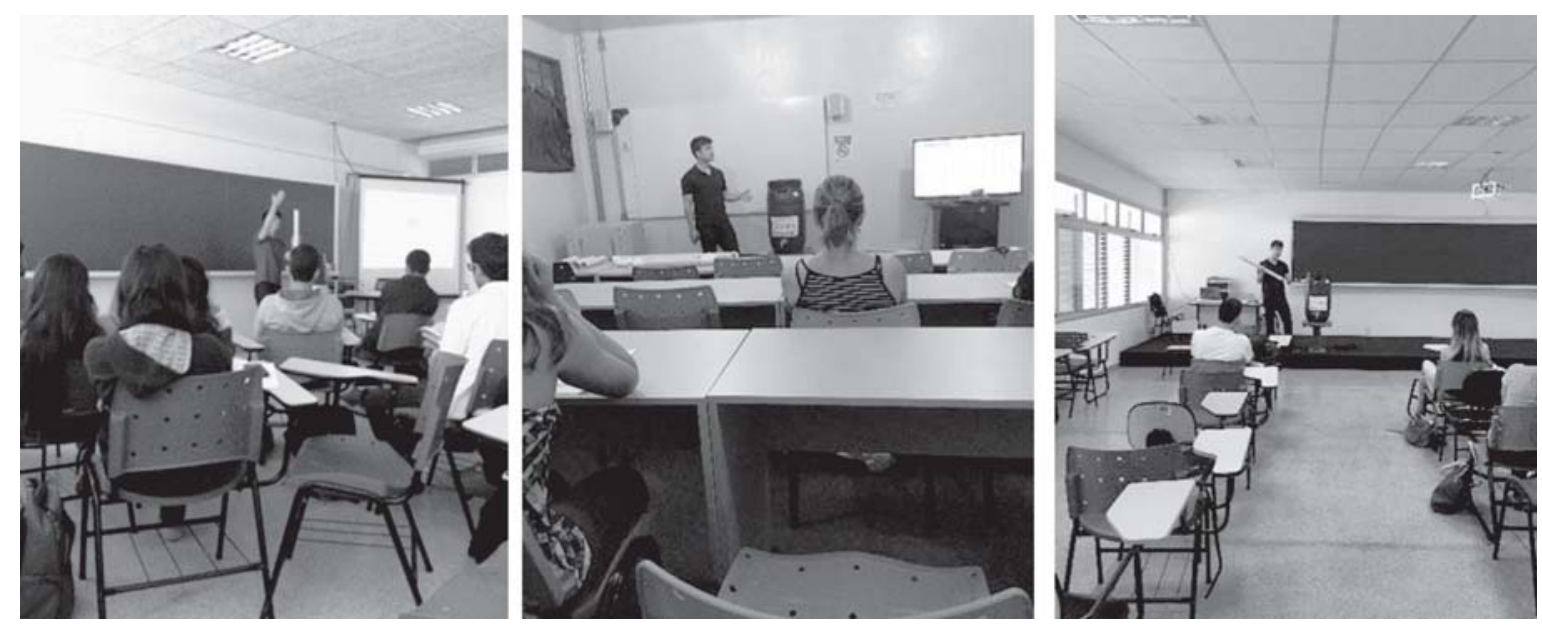

Figura 2 - Fotos das palestras. (a) Palestra oferecida à turma da disciplina Ciências Ambientais (ECV220); (b) Palestra que ocorreu na sede da UAITEC-CVT em Rio Paranaíba; (c) Palestra na UFV Campus Rio Paranaíba.

Fonte: Arquivo pessoal, 2017.

Além das palestras citadas, o projeto também teve participação, como apresentação oral, no Simpósio de Integração Acadêmica 2017 (SIA 2017) ${ }^{6}$ e no stand da Engenharia Civil da Mostra de Profissões da UFV-CRP, que ocorreu nos dias 23 e 24 de novembro do mesmo ano. A participação nesse evento ocorreu no primeiro dia, que contou com a participação de vários alunos do ensino médio de escolas de toda a região. Nessa mostra foi exposto a importância da universidade com o ensino, a pesquisa e a extensão e, com o auxílio do protótipo, houve a explicação do seu funcionamento para o aproveitamento da água de chuva.

\section{Avaliação das palestras}

Um questionário de avaliação foi proposto e entregue aos participantes das palestras para que as opiniões destes pudessem ser registradas. Dessa forma, foi possível verificar a qualidade das respostas obtidas conseguir um embasamento para aperfeiçoar os quesitos que não obtiveram bons resultados, em um primeiro momento.

\section{Resultados e discussão}

\section{Materiais didáticos utilizados}

Para a realização das palestras, utilizou-se, como recursos didáticos auxiliares, o protótipo de uma minicisterna, o qual é utilizado para demonstrar tanto o aproveitamento de água da chuva quanto o reúso de água cinza, a apresentação em slides e o modelo de cartilha. Nota-se a importância na utilização de cada material tendo em vista que são determinantes para adoção das práticas abordadas pelo público presente e a maior facilidade na explicação e demonstração das técnicas apresentadas, auxiliando na didática das palestras. Em suma, são meios muito eficazes para atrair a atenção das pessoas para os assuntos discutidos.

A tecnologia da minicisterna, proposta por Urbano (2014), possui todos os componentes necessários para um sistema para aproveitamento de água de chuva recomendado pela Associação Brasileira de Normas Técnicas (ABNT). Conforme ABNT (2007), devem ser considerados, no projeto de um reservatório da prática citada, componentes para remoção de detritos, como por exemplo de grades e telas, dispositivo de descarte da água de escoamento inicial, extravasor, dispositivo de esgotamento,

${ }^{6}$ O número de identificação do trabalho é 9064 e pode ser verificado através o link: <goo.gl/CKE7sY>. Acesso em: 12 fev. 2018 
cobertura, inspeção, ventilação e segurança. Ainda, "deve ser minimizado o turbilhonamento, dificultando a ressuspensão de sólidos e o arraste de materiais flutuantes" (ABNT, 2007).

Com a chuva, a água é recolhida da área de coleta, que, no caso de residências, são, geralmente, os telhados, e direcionada, pelas calhas e condutores verticais, até a minicisterna. O primeiro dispositivo que a água encontra é o filtro autolimpante com tela mosquiteiro que exerce a função de eliminar as sujeiras mais grosseiras. Logo depois, o descartador de primeiras águas, com ponta feita de tampa de garrafa PET com um pequeno furo, elimina as primeiras águas da chuva, que contém grande proporção de sujeira. Como a vazão que entra pelos condutores é maior que a que sai pelo furo da tampa, esse tubo irá encher e a água será direcionada para o redutor de turbulência, que é construído de tal forma para fazer com que a água entre por baixo do reservatório, evitando a mistura de pequenos sólidos. A água que excede o volume da bombona plástica é descartada através do extravasor, ou "ladrão", que possui, novamente, tela mosquiteiro, a fim de manter o reservatório seguro do mosquito Aedes Aegypti e outros pequenos animais. De forma semelhante para o armazenamento das águas cinza, o sistema é composto, simplesmente, pela torneira de utilização e a tampa de inspeção. O protótipo da minicisterna construído pode ser visto na Figura 3.
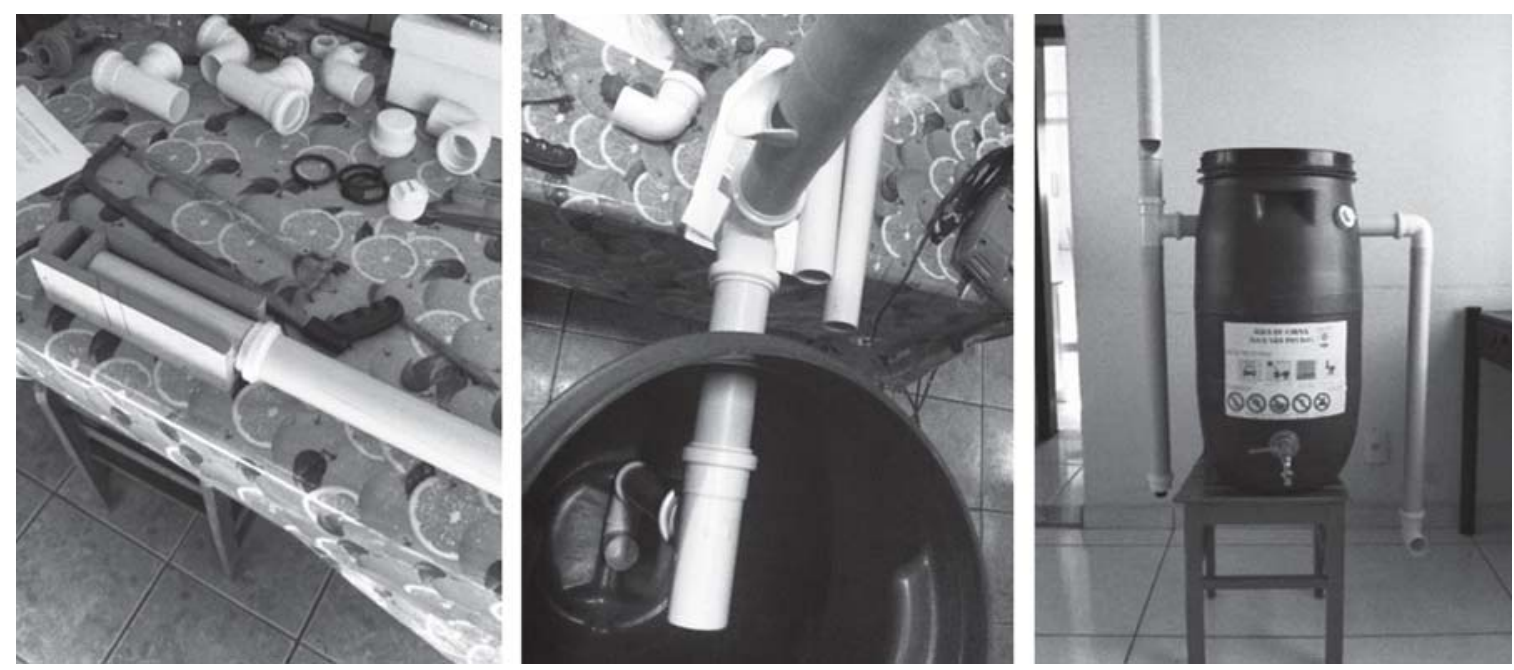

Figura 3 - Fotos da construção do protótipo de uma minicisterna. (a) Construção do filtro autolimpante; (b) Montagem do filtro autolimpante e redutor de turbulência. (c) Protótipo pronto da minicisterna com a sugestão de adesivo.

Fonte: Arquivo pessoal, 2017.

Como visto na Figura 3c, foi sugerido, também, a colagem de um adesivo nas bombonas plásticas, com o objetivo de alerta aos usuários para os cuidados no uso das águas dos reservatórios. A título de exemplo, foi confeccionado um adesivo para o direcionamento do uso das águas de chuva. Nele, contém, primeiramente, o aviso que a água é não-potável, além dos usos indicados, como lavagem de veículos e descargas em bacias sanitárias. Os cuidados, para não beber essa água e não utilizá-la para lavar as mãos, por exemplo, também foram colocados.

Após a pesquisa na literatura, como colocado anteriormente, foram selecionados alguns temas para fazer parte do escopo das palestras, os quais podem ser vistos no Anexo 1. A parte inicial da apresentação foi composta pela exposição do projeto, sua linha de extensão, o apoio financeiro pelo PIBEX e o palestrante, bolsista do mesmo. Posteriormente, na introdução das palestras procurou-se discutir temas que conscientizassem os participantes para a escassez hídrica que a sociedade enfrenta, as suas causas e que a solução pode estar na utilização das fontes alternativas.

Foram apresentados tópicos acerca do reúso de água e o conceito de águas negras, águas cinza escuras e claras. Os usos recomendados das águas cinza foram salientados, como para a lavagem de pisos e de automóveis, por exemplo, como sugerido pela ABNT (1997). Abordou-se, também, sobre os componentes básicos de um sistema de reúso de águas cinza e as etapas de um tratamento completo.

Quanto à captação e o uso da água de chuva, o assunto foi apresentado com um breve histórico sobre os povos antigos que tinham essa prática. Foram demonstrados, como para as águas cinza, os 
componentes básicos de um sistema de aproveitamento de água da chuva e suas respectivas funções, assim como os cuidados necessários para o reservatório.

As técnicas de baixo custo para o reúso de águas cinza apresentadas são caseiras e não requerem construções, instalação de equipamentos especiais ou reformas residenciais (ALVES et al., 2016). A abordagem foi feita somente em relação às águas da máquina de lavar roupas e do banho, as suas características, como armazená-las, por exemplo, utilizando a bombona plástica, semelhante à minicisterna, os seus usos e cuidados recomendados.

Por fim, para o aproveitamento das águas de chuva com custo inferior foram expostos sistemas para irrigação de jardins e a minicisterna. Utilizando o protótipo, foram exibidos cada um dos dispositivos e as funções deles esclarecidas. Os usos e os cuidados aconselhados também foram explicados.

Durante as palestras foi entregue a cada participante uma cartilha que contém as técnicas citadas, como pode ser analisado na Figura 4. Com o objetivo principal de orientar as pessoas para a execução correta das práticas, esse recurso é, ainda, fundamental para garantir uma comunicação efetiva e um aprendizado adequado, independentemente dos conhecimentos prévios dos participantes (CARDOSO et al., 2017).
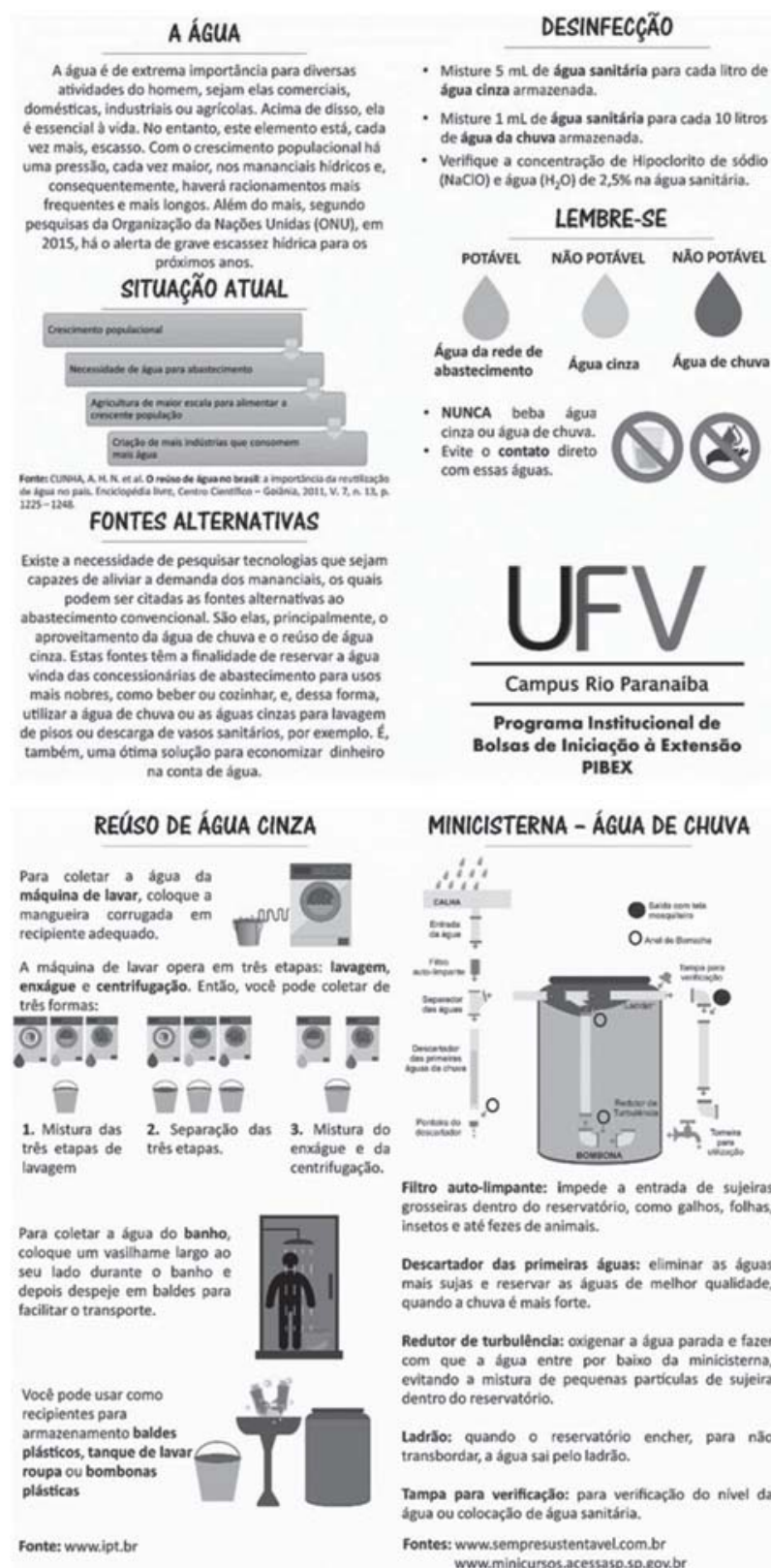

MINICISTERNA - ÁGUA DE CHUVA

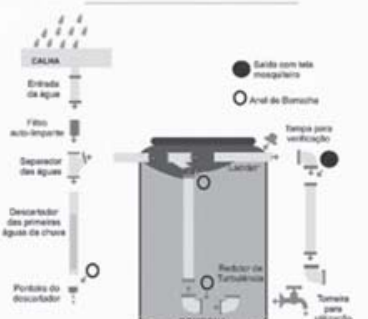

Filtro auto-limpante: impede a entrada de sujeiras
grosseiras dentro do reservatório, como gallhos, folhas, grosseiras dentro do reservatório, como galhos, follhas,

Descartador das primeiras dguas: eliminar as dguas mais sujas e resenvar as aguas de melhor qualicade.

Redutor de turbulência: oxigenar a dgua parada e fazer com que a bigua entre por baixo da minicisterna, dentro do reservatório.

Ladrăo: quando o reservatório encher, para nẫo transbordar, a água sai pelo ladrăo

Tampa para verificaşăo: para verificaçăo do nivel da úgua ou colocą̧̆o de dgua sanitária. Fontes: www.sempresustentavelcombr
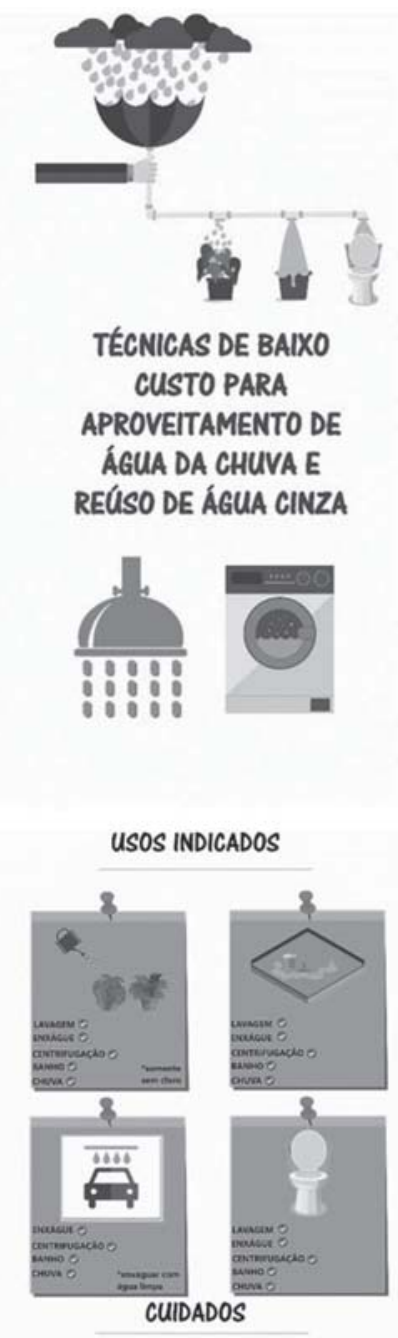

- Verifique se há substáncias nas águas cinzas como corantes e gordura que possam manchar pisos ou veiculos.

Nל̌o use àguas cinzas para regar hortas

NJo use dguas cinzas para regar jardins e
gramados que ocorrerd contato da superficie

com o corpo.

Figura 4 - Cartilha distribuída aos participantes das palestras. (a) Parte externa da cartilha. (b) Parte interna da cartilha.

Fonte: Elaborada pelos autores, 2017. 


\section{Análise das palestras por meio de questionário de avaliação}

As três palestras foram acompanhadas por 45 pessoas e, a cada uma, foi entregue um questionário de avaliação. Nessa enquete, as perguntas tinham como possibilidade de resposta os números 1 a 5, sendo que 1 representa a pior avaliação e 5 a melhor. As perguntas estão disponíveis no Anexo 2 e os resultados podem ser vistos na Tabela 1.

\begin{tabular}{|c|c|c|c|c|c|}
\hline Pergunta & 5 & 4 & 3 & 2 & 1 \\
\hline Qual é a nota geral que você dá ao evento? & $95,45 \%$ & $4,55 \%$ & $0,00 \%$ & $0,00 \%$ & $0,00 \%$ \\
\hline Quanto você acha importante o conteúdo abordado? & $93,18 \%$ & $4,55 \%$ & $0,00 \%$ & $2,27 \%$ & $0,00 \%$ \\
\hline O conteúdo foi abordado de maneira clara e concisa? & $95,45 \%$ & $4,55 \%$ & $0,00 \%$ & $0,00 \%$ & $0,00 \%$ \\
\hline Qual foi a qualidade da apresentação? & $93,18 \%$ & $6,82 \%$ & $0,00 \%$ & $0,00 \%$ & $0,00 \%$ \\
\hline Qual foi a qualidade do material didático fornecido? (Cartilha) & $93,18 \%$ & $6,82 \%$ & $0,00 \%$ & $0,00 \%$ & $0,00 \%$ \\
\hline Você acha que as práticas citadas são de fácil aplicação à rotina da população? & $34,09 \%$ & $40,91 \%$ & $22,73 \%$ & $2,27 \%$ & $0,00 \%$ \\
\hline Quais são as chances de você inserir as práticas citadas à sua rotina? & $20,45 \%$ & $36,36 \%$ & $25,00 \%$ & $15,91 \%$ & $2,27 \%$ \\
\hline
\end{tabular}

Conforme o resultado apresentado, de um modo geral, o projeto obteve um excelente resultado em relação a sua qualidade, com nota 5, majoritariamente $(95,45 \%)$. A abordagem inicial da palestra, tendo o objetivo de conscientizar as pessoas acerca do uso de fontes alternativas também foi muito boa, visto que a maior parte avaliou com nota $5(93,18 \%)$ a importância do assunto discutido.

A palestra, especificamente, também alcançou resultados bastante satisfatórios. Quanto ao modo como os assuntos foram tratados, de forma concisa e clara, $95,45 \%$ do público avaliou com a nota 5 , a qualidade da apresentação em slides com $93,18 \%$ da mesma nota e, com igual porcentagem, nota-se que o público aprovou a cartilha criada. Em relação às duas últimas perguntas, acredita-se que o resultado é devido, principalmente, à utilização de elementos visuais para expor os assuntos apresentados.

A maior parte do público julgou, com nota 4 , que as práticas citadas são facilmente aplicáveis à população $(40,91 \%)$ e, em relação a cada um colocar em prática as técnicas citadas nas palestras, $36,36 \%$ avaliaram com a mesma nota. Considera-se com bastante contento o resultado, no entanto, busca-se melhorá-lo ainda mais. Apenas 34,09\% e 20,45\% das pessoas que frequentaram as palestras julgaram com nota máxima as mesmas perguntas colocadas anteriormente, respectivamente. Acredita-se que esse resultado se deve ao fato de que as técnicas de baixo custo demandam tempo do dia a dia para sua execução, principalmente no que diz respeito ao reúso de águas cinza. Para continuidade do projeto, é recomendado mais pesquisa em torno dessas práticas, desenvolvendo sua facilidade e mantendo o baixo custo.

\section{Conclusões}

O projeto contou com a linha de pesquisa para a estruturação das palestras. Considera-se o ensino para a realização delas, contribuindo para as habilidades de comunicação do bolsista. E, por fim, com a extensão, o conhecimento técnico adquirido foi passado às pessoas, inserindo a Universidade na realidade da sociedade, além de colaborar para o desenvolvimento das características humanitárias dos membros do projeto.

Visto que as questões levantadas ao longo do artigo frente à situação de escassez hídrica, o reúso de águas cinza e o aproveitamento de água de chuva têm grande potencial para minimizar esse problema. Em Rio Paranaíba, por meio do presente projeto, essa cultura foi iniciada e precisa continuar com a contribuição de cada participante da palestra, sendo um indivíduo divulgador.

Além do impacto ambiental do projeto, é possível, ainda, a abertura de um novo mercado na cidade. Com a construção das minicisternas para a água de chuva, ou a bombona plástica com a torneira de utilização e a tampa de inspeção para uso e armazenamento das águas cinza, há pessoas que prefiram comprá-las prontas que fazê-las. Assim, há a possibilidade de haver geração de renda para aqueles dispostos a construir para a venda.

Sugere-se, para o prosseguimento da disseminação das práticas citadas, que as palestras também sejam realizadas em ambientes escolares de diversas idades e, dessa forma, direcionáveis a cada público alvo. Isso é esperado pois o protótipo da minicisterna foi doado para a ONG Engenheiros Sem Fronteiras Núcleo Rio Paranaíba ${ }^{7}$ que buscará dar continuidade ao propósito.

${ }^{7}$ O Engenheiros Sem Fronteiras Núcleo Rio Paranaíba é uma organização sem fins lucrativos que atua utilizando engenharia e educação em prol do desenvolvimento social. A página da instituição pode ser acessada pelo link: <goo.gl/j33Kuf>. Acesso em: 12 fev. 2018. 


\section{Fontes de financiamento}

O Projeto "Apoio à disseminação de técnicas de baixo custo para aproveitamento de água de chuva e reúso de água cinza" recebeu o apoio da Universidade Federal de Viçosa Campus Rio Paranaíba (UFV-CRP), por meio da Pró-Reitoria de Extensão e Cultura (PEC), após ser aprovado no Edital $n^{\circ}$ 02/2016 do Programa Institucional de Bolsas de Iniciação à Extensão Universitária (PIBEX).

\section{Agradecimentos}

Ao professor Lineker Coelho pela idealização do projeto e sempre solicito às dúvidas. À professora Mariana Miziara pelo auxílio de sempre e espaço cedido para a palestra na disciplina ECV 220. À Henrique Tadeu, Débora Couto, Flávia Garcia e Heitor Fonseca pelo auxílio, conselhos e amizade. À Elmo Fonseca e Veida Fonseca pelo auxílio na construção da minicisterna. À Maíra Queiroz e Laíse Lopes pela assistência em levar os materiais didáticos para as palestras. À Rádio Maximus e Comunicação Social UFV-CRP pelo apoio na divulgação das mesmas. À UAI-TEC unidade Rio Paranaíba e UFV-CRP pelo espaço cedido para a realização das palestras.

\section{Referências}

ALVES, W. C.; ZANELLA, L.; CASTRO, J. R. de; QUEIROZ, R. S. de. Manual para aproveitamento emergencial de águas cinza do banho e da máquina de lavar. Instituto de Pesquisas Tecnológicas (IPT). São Paulo, 2016. 32p. Disponível em: <goo.gl/0k95X0>. Acesso em: 5 fev. 2018.

ANDREOLI, F. C. Aplicação de tecnologia social em projetos de extensão em saneamento. Revista de Extensão e Cultura USP, São Paulo, maio de 2016, n. 15 - Suplemento, p. 41 - 49.

ASSOCIAÇÃO BRASILEIRA DE NORMAS TÉCNICAS. NBR 13969: tanques sépticos: unidades de tratamento complementar e disposição final dos efluentes líquidos - projeto, construção e operação. Rio de Janeiro, 1997. 60p

ASSOCIAÇÃO BRASILEIRA DE NORMAS TÉCNICAS. NBR 15527: Água de chuva - aproveitamento de coberturas em áreas urbanas para fins não potáveis - requisitos. Rio de Janeiro, 2007. 08p.

CARDOSO, Y. B. A. B. da S. B.; AMOGLIA, S. M; MCCLELLAND, J. L.; TEIXEIRA, A. F.; MELO, L. F. Projeto Sabão Ecológico: uma estratégia educacional para a reciclagem do óleo de cozinha no munícipio de Viçosa. Revista ELO, Viçosa, dezembro de 2017, v. 06, n. 03, p. 33 - 44.

CUBA, R. M. F.; MANZANO, D. P. Avaliação técnica e econômica do reúso de águas cinza em aparelhos sanitários. Colloquium Exactarum, Presidente Prudente, set.-out. 2014, v. 6, n. 3, p. 72 - 83.

CUNHA, A. H. N.; OLIVEIRA, T. H. de; FERREIRA, R. B.; MILHARDES, A. L. M.; SILVA, S. M. da C. e. O reúso de água no Brasil: a importância da reutilização de água no país. Enciclopédia livre, Centro Científico, Goiânia, 2011, v. 7, n. 13, p. 1225 - 1248.

DANTAS, D. L.; SALES, A. W. C. Aspectos ambientais, sociais e jurídicos do reúso da água. Revista de Gestão Social e Ambiental, São Paulo, set. - dez. 2009, v. 3, n. 3, p. 4 - 19.

FIORI, S.; FERNANDES, V. M. C.; PIZZO, H. S. Avaliação do potencial de reúso de águas cinzas em edificações. I Conferência latino-americana de construção sustentável. X Encontro Nacional de Tecnologia do Ambiente Construído. São Paulo, 2004.

FIORI, S.; FERNANDES, V. M. C; PIZZO, H. S. Avaliação qualitativa e quantitativa do reúso de águas cinzas em edificações. Ambiente Construído, Porto Alegre, jan.-mar. 2006, v. 6, n 1, p. 19-30.

HAFNER, A. V. Conservação e reúso de água em edificações - experiências nacionais e internacionais. Dissertação (Mestrado) - Universidade Federal do Rio de Janeiro. Rio de Janeiro, 2007. 161 p.

HESPANHOL, I. Possibilidades de reúso de água no Brasil: Agricultura, Indústria, Municípios, Recarga de Aquíferos. Revista Brasileira de Recursos Hídricos, out. - dez. 2002, p. 75 - 95. 
INSTITUTO BRASILEIRO DE GEOGRAFIA E ESTATÍSTICA - IBGE. Projeção da população do Brasil por sexo e idade para o período 2000-2060. 2013. Disponível em: <goo.gl/ANNL9R>. Acesso em: 3 fev. 2018.

MAY, S. Caracterização, tratamento e reúso de águas cinza e aproveitamento de águas pluviais em edificações. Tese (Doutorado) - Escola Politécnica da Universidade de São Paulo. Departamento de Engenharia Hidráulica e Sanitária. São Paulo, 2009. 222p.

MAY, S. Estudo da viabilidade do aproveitamento de água de chuva para consumo não potável em edificações. Dissertação (Mestrado) - Escola Politécnica da Universidade de São Paulo. Departamento de Construção Civil. São Paulo, 2004. 159 p.

MUNHOZ, F. D. Reúso de água em residências de pequeno e médio porte com sistema pré-fabricado. Trabalho de Conclusão de Curso. Universidade Anhembi Morumbi. São Paulo, 2006. 46 p.

ONU Brasil. Até 2030 planeta pode enfrentar déficit de água de até 40\%, alerta relatório da ONU. 2015. Disponível em: <goo.gl/R2Dhmp>. Acesso em: 3 fev. 2018.

URBANO, E. Projeto experimental de aproveitamento de água da chuva com a tecnologia da minicisterna para residência urbana. 2014. Disponível em: <goo.gl/dYxlCo> Acesso em: 5 fev. 2018.

ZANELLA, L. Manual para captação emergencial e uso doméstico de água de chuva. Instituto de Pesquisas Tecnológicas (IPT). São Paulo, 2015. 28 p. Disponível em: <goo.gl/8yAhuD>. Acesso em: 5 fev. 2018.

\section{Anexos}

\section{Anexo 1: Conteúdos abordados nas palestras}

1. Introdução

1.1 A água;

1.2 Alerta da ONU;

1.3 A água no mundo;

1.4 Ciclo da água;

1.5 População e água;

1.6 Fontes alternativas.

2. Águas cinza

2.1 Reúso de água;

2.2 Conceitos dos efluentes gerados no ambiente doméstico;

2.3 Consumo de águas nas residências;

2.4 Usos das águas cinza;

2.5 Componentes de um sistema de reúso de águas cinza;

2.6 Tratamento completo.

3. Água de chuva

3.1 Histórico;

3.2 Componentes de um sistema de aproveitamento de água da chuva;

3.3 Cuidados com o sistema de aproveitamento de água da chuva.

4. Técnicas de baixo custo para aproveitamento de águas cinza do banho e da máquina de lavar roupas

4.1 Características das águas cinza;

4.2 Qualidade das águas cinza;

4.3 Usos das águas cinza e os seus cuidados;

4.4 Como coletar a água da máquina de lavar roupas;

4.5 Como coletar a água do banho;

4.6 Como armazenar a água.

5 Técnicas de coleta de água de chuva para irrigação de jardins

6 Captação e uso da água de chuva 
6.1 Limpeza do ambiente;

6.2 Escolha do reservatório;

6.3 Local do reservatório;

6.4 Funcionamento de uma minicisterna;

6.5 Cuidados com o armazenamento da água de chuva;

6.6 Usos indicados para a água de chuva.

7 Referências

Anexo 2: Questionário de avaliação da palestra

1. Qual é a nota geral que você dá ao evento?

2. Quanto você acha importante o conteúdo abordado?

3. O conteúdo foi abordado de maneira clara e concisa?

4. Qual foi a qualidade da apresentação?

5. Qual foi a qualidade do material didático fornecido (cartilha)?

6. Você acha que as práticas citadas são de fácil aplicação à rotina da população?

7. Quais são as chances de você inserir as práticas citadas à sua rotina?

Recebido para publicação em 11/3/2018 e aprovado em 14/06/2018. 